\title{
Easy to Perform Physical Performance Tests to Identify COPD Patients with Low Physical Activity in Clinical Practice
}

This article was published in the following Dove Press journal: International Journal of Chronic Obstructive Pulmonary Disease

\author{
Zinka Matkovic $\mathbb{1}^{\prime}$ \\ Neven Tudoric ${ }^{1,2}$ \\ Danijel Cvetko ${ }^{3}$ \\ Cristina Esquinas ${ }^{4}$ \\ Dario Rahelic ${ }^{2,5,6}$ \\ Marko Zarak ${ }^{7}$ \\ Marc Miravitlles (D) ${ }^{4}$ \\ 'Department of Internal Medicine, \\ Division of Pulmonary Medicine, Dubrava \\ University Hospital, Zagreb, Croatia; \\ ${ }^{2}$ University of Zagreb, School of \\ Medicine, Zagreb, Croatia; ${ }^{3}$ Department \\ of Diagnostic and Interventional \\ Radiology, Dubrava University Hospital, \\ Zagreb, Croatia; ${ }^{4}$ Pneumology \\ Department, Hospital Universitari Vall \\ d'Hebron/Vall d'Hebron Institut de \\ Recerca (VHIR), CIBER de Enfermedades \\ Respiratorias (CIBERES), Barcelona, \\ Spain; ${ }^{5}$ Vuk Vrhovac University Clinic for \\ Diabetes, Endocrinology and Metabolic \\ Diseases, Merkur University Hospital, \\ Zagreb, Croatia; ' ${ }^{6}$ niversity of Osijek, \\ School of Medicine, Osijek, Croatia; \\ ${ }^{7}$ Department of Laboratory Diagnostics, \\ Dubrava University Hospital, Zagreb, \\ Croatia
}

Background: The study investigates which physical performance or muscle function/mass tests significantly correlate with objectively measured physical activity (PA) in patients with chronic obstructive pulmonary disease (COPD) and could potentially serve to identify physically inactive COPD patients in routine clinical practice.

Methods: A cross-sectional, observational study was conducted in outpatients with moderate to very severe COPD. PA was measured during one week with the StepWatch Activity Monitor $^{\circledR}$, an ankle-worn accelerometer, and expressed in steps per day. Physical fitness and peripheral muscle function/mass were evaluated by the 4-meter gait speed (4MGS) test, the 6-minute walk distance (6MWD), the 30-second chair stand test (30sCST), the timed up and go test (TUGT), handgrip strength, arm muscle area, calf circumference, the fat-free mass index (FFMI), and ultrasound measurement of the quadriceps muscle. Spearman's rank correlation analysis and ROC analysis were performed.

Results: The study population ( $\mathrm{N}=111,69 \%$ men, mean age 68 years) walked a mean of 8059 steps/day. The daily step count strongly correlated with the 6MWD (rho $=0.684$, $\mathrm{p}<0.001)$ and moderately with the 4MGS $(\mathrm{rho}=0.464, \mathrm{p}<0.001)$, the TUGT $(\mathrm{rho}=-0.463$, $\mathrm{p}<0.001$ ), and the $30 \mathrm{sCST}(\mathrm{rho}=0.402, \mathrm{p}<0.001)$. The correlation with the FFMI was weak $(r h o=0.210, p=0.027)$, while the other parameters did not significantly correlate with the daily step count. The $6 \mathrm{MWD}$ had the best discriminative power to identify patients with very low PA defined as $<5000$ steps/day (AUC $=0.802$ [95\% CI: $0.720-0.884$ ], $\mathrm{p}<0.001$ ), followed by the TUGT, the $4 \mathrm{MGS}$, and the $30 \mathrm{sCST}$.

Conclusion: The 6MWD, the 4MGS, the TUGT, and the 30sCST are easy to perform in any clinical setting and may be used by clinicians in the screening of physically inactive COPD patients.

Keywords: chronic obstructive pulmonary disease, physical activity, gait speed, muscle function, muscle mass, exercise capacity

\section{Introduction}

Patients with chronic obstructive pulmonary disease (COPD) have a lower level and intensity of physical activity (PA) compared to age-matched healthy individuals and even to patients with other chronic diseases. ${ }^{1,2}$ Physical inactivity and sedentary lifestyle become more evident with increasing COPD severity as a result of progressive ventilatory limitation, cardiac impairment, peripheral muscle dysfunction, and psychological factors. ${ }^{3,4}$ There is a growing body of evidence linking low PA and exercise intolerance in COPD patients with multiple negative clinical
Correspondence: Zinka Matkovic Department of Internal Medicine, Division of Pulmonary Medicine, Dubrava University Hospital, Avenija Gojka Šuška

6, Zagreb 10000, Croatia

$\mathrm{Tel} / \mathrm{Fax}+385 \mathrm{I} 2902488$

Email zinka.matkovic@gmail.com 
implications, such as functional limitation and disability, impaired health-related quality of life, increased risk of exacerbation, a higher hospital admission rate, development of anxiety and depression, and increased mortality. $^{5-10}$

Although the main focus of the management of COPD is respiratory symptoms and exacerbations, clinicians are becoming increasingly aware of the frequent extrapulmonary manifestations as well as the negative consequences of reduced PA in patients with COPD ${ }^{11}$ However, PA is still rarely measured in clinical practice, and a lack of time and equipment are just some of the multiple reasons for this. PA questionnaires and diaries are the simplest and the cheapest methods for this purpose, but their main limitation is a lack of accuracy due to recall bias. ${ }^{12}$ Devices such as pedometers or step counters are relatively inexpensive and available, although they usually underestimate activity in individuals with slow walking speed, such as those with advanced COPD. ${ }^{13}$ The preferred instruments for assessing PA in the ambulatory setting are accelerometers or activity monitors, the reliability and validity of which have been proven in different populations, including COPD patients; ${ }^{14,15}$ however, their use in routine clinical practice is still mainly limited by their price. In contrast, we hypothesize that some easy to perform physical performance tests or measures of muscle function or muscle mass may be useful to detect COPD patients with severely reduced PA in clinical practice.

The aim of this study was to investigate which physical performance or muscle function/mass tests significantly correlate with objectively measured PA and may be used in routine clinical practice to identify patients with severely reduced levels of PA.

\section{Methods}

\section{Study Design and Participants}

This was a single-center cross-sectional observational study conducted in outpatients with stable COPD. The details of the study have been published previously. ${ }^{16}$ Briefly, participants were recruited from a pulmonary outpatient clinic. They were $\geq 40$ years of age, were smokers or ex-smokers of $\geq 10$ pack-years, with a documented COPD history $\geq 1$ year, and with a post-bronchodilator ratio of the forced expiratory volume in one second $\left(\mathrm{FEV}_{1}\right)$ to the forced vital capacity $(\mathrm{FVC})<0.70$, and $\mathrm{FEV}_{1}<80 \%$ predicted. The key exclusion criteria included concomitant conditions that might influence PA or nutritional status such as unstable cardiovascular disease, limitation to walk due to neurological or osteomuscular disorders, active malignant disease, end-stage renal or liver disease, uncontrolled diabetes or thyroid disease, dementia, sustained systemic corticosteroid therapy, COPD exacerbation within three months of enrolment, and asthma or another active respiratory disease besides COPD.

The study was conducted in accordance with the Declaration of Helsinki and was approved by the Ethics Committee of the Dubrava University Hospital (Zagreb, Croatia), and all participants signed informed consent to participate.

\section{Measurements}

Sociodemographic and clinical data related to COPD and comorbidities were collected. Respiratory symptoms were evaluated by the Modified Medical Research Council (mMRC) dyspnea scale ${ }^{17}$ and the COPD Assessment Test (CAT). ${ }^{18}$ COPD exacerbations requiring treatment with antibiotics, systemic corticosteroids and/or hospitalization in the previous year were recorded. The Charlson index ${ }^{19}$ was used for the evaluation of comorbidities based on the medical history and electronic health care database.

Pre- and post-bronchodilator spirometry, diffusing capacity of the lung for carbon monoxide, and body plethysmography were performed (Vmax Series Software Version 20-7, VIASYS Healthcare Inc., SensorMedics Corporation, USA) according to international guidelines. ${ }^{20,21}$ Arterial blood gases were analyzed under resting conditions in room air.

The daily step count was measured with the StepWatch Activity Monitor ${ }^{\circledR}$ (SAM) (Modus Health IIc, Washington DC, USA). SAM is an ankle-worn accelerometer proven to be a reliable method for measuring PA in patients with COPD. ${ }^{6,15}$ Patients were instructed to wear the SAM during $7 \pm 2$ consecutive days except while washing and sleeping, to perform physical activity as usual, and to return the device at the second study visit at which time the data were downloaded. The days of the study visits, as well as no-wear days ( $<8$ hours of wear time), were excluded from the analysis, and the average daily step count was recorded. ${ }^{16}$

Five different tests were used for the assessment of physical fitness and/or muscle function, and four more methods were applied to measure muscle mass. The 6-minute walk test (6MWT), the 4-meter gait speed (4MGS) test, 30second chair stand test (30sCST), and the timed up and go 
test (TUGT) were performed in a standardized way as described previously. ${ }^{22-25}$ Patients with chronic respiratory insufficiency were provided with supplemental oxygen when performing walking tests. The $4 \mathrm{MGS}$ and the TUGT were carried out twice, and the best result was recorded.

Maximal handgrip strength (kg) was measured with a handheld dynamometer (KERN MAP 80K1, Version 1.2 08/2012, KERN \& Sohn GmbH, Germany) in a sitting position while the hand was unsupported with the elbow at $90^{\circ}$ flexion and the underarm and wrist in neutral positions. $^{26}$ Three measurements were performed with each hand, and the best value was used in the analysis.

Fat-free mass was assessed by dual energy X-ray absorptiometry (DEXA) total body scan (Lunar PRODIGY Primo, enCORE Software version 11.1, GE Healthcare, 2007), and the fat-free mass index (FFMI) was calculated by dividing the fat-free mass by height squared and expressed in $\mathrm{kg} / \mathrm{m}^{2}$. In the additional evaluation of muscle mass, several anthropometric measurements and calculations were carried out by routine methods: ${ }^{27}$ calf circumference (CC), mid-upper arm circumference (MUAC), arm muscle area (AMA), and triceps skin fold (TSF). The TSF (mm) was measured three times with a caliper (Harpenden Skinfold Caliper, British Indicators LTD, England), while the CC (cm) and the MUAC $(\mathrm{cm})$ were measured twice with a tape measure, and the mean values were recorded. The AMA was calculated by the equation

$\operatorname{AMA}\left(\mathrm{cm}^{2}\right)=[\operatorname{MUAC}(\mathrm{cm})-0.314 \times \operatorname{TSF}(\mathrm{mm})]^{2} /(4 \times 3.14)$

Ultrasound measurement of quadriceps rectus femoris cross-sectional area $\left(\mathrm{RF}_{\mathrm{CSA}}\right)$ was done by an experienced radiologist using B-mode ultrasonography with an $8 \mathrm{MHz}$, $5.6 \mathrm{~cm}$ linear transducer array (General Electric Logiq E9, General Electric Company, WI, USA) according to a technique described by Seymour et al. ${ }^{28}$ Briefly, the patient was in supine position with the right leg in passive extension, and the transducer was placed perpendicular to the long axis of the thigh on its superior aspect, three-fifths of the distance along a line from the anterior superior iliac spine to the superior patellar border. $\mathrm{RF}_{\mathrm{CSA}}$ was calculated using a planimetric technique after manually outlining the echogenic line of the rectus femoris on a frozen image, and the average of three consecutive measurements was recorded.

\section{Statistical Analysis}

Continuous variables were presented in means (standard deviations $[\mathrm{SD}])$, or medians $\left(1^{\text {st }}\right.$ quartile; $3^{\text {rd }}$ quartile $)$ in the case of non-normal distribution. Absolute numbers (percentages) were used for categorical variables. Linear relationship between variables was studied using the Spearman correlation test. Receiver operating characteristic (ROC) curves were calculated to identify both the discriminative capacity of each test (area under the curve - AUC) and the potential dichotomic cut-offs for identification of patients with severely reduced levels of PA, using the threshold of 5000 steps/day, according to international recommendations. ${ }^{29}$ The sensitivity $(\mathrm{Se})$ and specificity (Sp), and positive predictive (PPV) and negative predictive values (NPV) were calculated for each of the tests in relation to the identification of patients with reduced PA. All the tests were conducted at a level of significance of $\alpha=0.05$. The SPSS version 20 software (IBM Corp., Armonk, NY, USA) was used for all the analyses.

\section{Results \\ Patient Characteristics}

A total of 112 patients fulfilling the study criteria were recruited, and 111 (76 men, mean age 67.7 [SD 7.8] years) completed all the protocol-related procedures. Table 1 shows the patient characteristics. The mean $\mathrm{FEV}_{1}$ was $48.9 \%(15 \%)$, the CAT score 17.9 (6.4), and the mean mMRC dyspnea grade was 2.0 (1.0). Forty-two (37.8\%) patients presented at least one COPD exacerbation in the previous year, mean 1.2 (1.4), maximum 8, and the Charlson comorbidity index was 1.8 (1.0). Long-acting bronchodilators were the most commonly used COPD medications, and 58 patients (52\%) were receiving inhaled corticosteroids (Table 1).

\section{Evaluation of Physical Activity}

The 111 patients studied provided a valid registry of PA during the days required. The readings demonstrated that the study population was active a mean of 323.4 (134.2) minutes per day, namely $22.5 \%(9.3 \%)$ of $24 \mathrm{~h}$, and the average daily step count was 8059 steps/day (4757, range 220-23,342). Figure 1 shows the distribution of the levels of activity intensity.

\section{Physical Fitness and Muscle Function/Mass Measurements}

The results of the different tests of physical performance and muscle function/mass are shown in Table 2. Patients walked a mean of $376 \mathrm{~m}$ (119) in the 6MWT, had a mean 
Table I Patient Characteristics

\begin{tabular}{|l|l|}
\hline Parameter & $\begin{array}{l}\text { Patients } \\
\text { (n=I I I) }\end{array}$ \\
\hline Age, years & $67.7(7.8)$ \\
Sex, male (\%) & $76(68.5 \%)$ \\
Smoking status & \\
Smokers & $39(35.1 \%)$ \\
Ex-smokers & $72(64.9 \%)$ \\
Smoking history, pack-years & $43.9(24.8)$ \\
Charlson comorbidity index & $1.8(1.0)$ \\
COPD exacerbations in the last year & $1.2(1.4)$ \\
mMRC dyspnea scale & $2.0(1.0)$ \\
CAT score & $17.9(6.4)$ \\
Post-bronchodilator FVC, \% predicted & $90.8(19.0)$ \\
Post-bronchodilator FEV, \% predicted & $48.9(15.0)$ \\
Post-bronchodilator FEV/FVC & $0.43(0.1 \mathrm{I})$ \\
TLC, \% predicted & $110.5(24.6)$ \\
RV, \% predicted & $159.5(62.2)$ \\
DLCO/VA, \% predicted & $70.3(22.9)$ \\
PO, kPa & $9.2(1.4)$ \\
PCO, kPa & $5.6(0.7)$ \\
\hline Treatment & \\
Short-acting beta adrenergics & $86(78 \%)$ \\
Short-acting antimuscarinic agents & $22(20 \%)$ \\
Long-acting beta adrenergic & $105(95 \%)$ \\
Long-acting antimuscarinic agents & $93(84 \%)$ \\
Inhaled corticosteroids & $58(52 \%)$ \\
Theophylline & $4 I(37 \%)$ \\
Roflumilast & $1(1 \%)$ \\
Long-term oxygen therapy & $12(11 \%)$ \\
\hline
\end{tabular}

Note: Data are presented as means (standard deviation) or numbers (\%), as appropriate.

Abbreviations: CAT, COPD Assessment Test; COPD, chronic obstructive pulmonary disease; DLCO/VA, diffusing capacity of the lung for carbon monoxide per liter of alveolar volume; $\mathrm{FEV}_{1}$, forced expiratory volume in one second; $\mathrm{FVC}$, forced vital capacity; mMRC, modified Medical Research Council; $\mathrm{pCO}_{2}$, partial pressure of carbon-dioxide in arterial blood; $\mathrm{pO}_{2}$, partial pressure of oxygen in arterial blood; $\mathrm{RV}$, residual volume; TLC, total lung capacity.

walking speed of $0.89 \mathrm{~m} / \mathrm{s}(0.22)$ in the $4 \mathrm{MGS}$ test, completed 11 (3) full stands in the 30sCST, and needed 10.3 s (3.3) to perform the TUGT. Most tests showed a high range of values indicating different degrees of physical and muscle impairment in the study population.

\section{Correlations Between Physical Activity and Measurements of Physical Fitness and Muscle Function/Mass}

Table 3 and Figure 2 show the results of the Spearman correlation analysis between PA and parameters of physical fitness and muscle function/mass. There was a strong correlation between the daily step count and the 6-minute walk distance (6MWD), and a moderate correlation between the daily step count and the 4MGS, the TUGT, and the 30sCST. The FFMI and PA showed only a weak correlation. In contrast, there were no significant correlations between the daily step count and handgrip strength, $\mathrm{CC}$, AMA and $\mathrm{RF}_{\mathrm{CSA}}$.

\section{Predictive Value of Different Physical Performance Tests in the Prediction of a Very Low Level of Physical Activity}

Among the variables analyzed, the 6MWD had the best discriminative power to identify patients with very low PA defined as less than 5000 steps/day $(\mathrm{AUC}=0.802$ [95\% CI: $0.720-0.884$ ], $\mathrm{p}<0.001$ ), followed by the TUGT, the 4MGS, and the 30sCST (Table 4). The best thresholds of these tests to identify inactive COPD patients are shown in Table 4. The 6MWD showed a Se of $80.6 \%$, a Sp of $68 \%$, a PPV of $54.7 \%$ and a NPV of $87.9 \%$. For the TUGT, the Se was $63.9 \%$, the Sp 68\%, the PPV $49 \%$ and the NPV $79.7 \%$; being $55.6 \%, 78.7 \%, 55.6 \%$ and $78.7 \%$, respectively, for the 4MGS and finally, 36.1\%, 33.3\%, 20.6\% and $52.1 \%$, respectively, for the $30 \mathrm{sCST}$. The remaining tests did not show a significant discriminative power for reduced $\mathrm{PA}$.

Among the four tests with significant predictive value in the prediction of low PA, we used three that are the easiest to perform, namely the 4MGS, the 30sCST, and the TUGT to calculate a probability of a very low level of PA based on the results of these tests (Table 5). A patient with a $4 \mathrm{MGS}<0.8 \mathrm{~m} / \mathrm{s},<11$ stands in the $30 \mathrm{sCST}$ and needs $>10 \mathrm{~s}$ to perform the TUGT has a $70 \%$ probability of walking less than 5000 steps per day.

\section{Discussion}

The results of this study indicate that several simple physical performance tests demonstrate a significant correlation with objectively measured PA in patients with COPD. This correlation was strong for the 6MWD, moderate for the 4MGS, the TUGT, and the 30sCST, and weak for the FFMI. The 6MWD had the best discriminative power to identify physically inactive COPD patients.

Sedentarism has been recognized as an important issue in the COPD population because of its high prevalence and negative consequences. Fortunately, PA is susceptible to improvement with the appropriate strategies in most respiratory patients, but before any actions are undertaken it is important to assess the initial level of PA in daily life. 
A

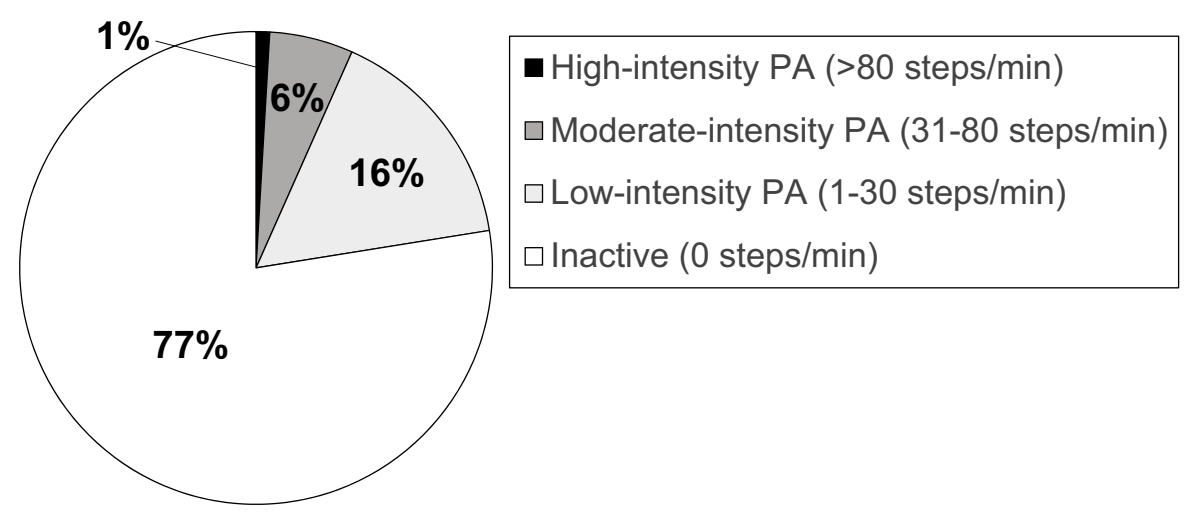

B

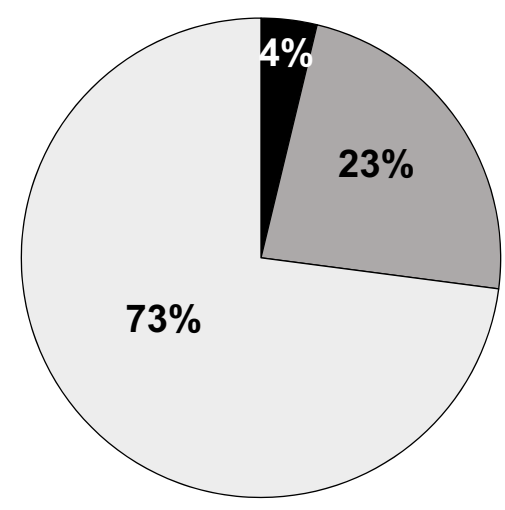

Figure I Intensity of physical activity in the study population. (A) Percentages of daily time. (B) Percentages of active time. Abbreviation: PA, physical activity.

However, the assessment of PA is time consuming and requires additional equipment, which makes it impractical to integrate into the usually busy clinical routine. Hence, the aim of the present study was to measure PA in "reallife" COPD patients with a wide range of ventilatory impairment and to evaluate whether some simple, rapid, inexpensive and clinically available tests of physical fitness and muscle function/mass show a good correlation with objectively measured PA, and may potentially serve as a screening tool for identification of inactive COPD patients in clinical practice.

Previous studies have shown that most COPD patients spend significantly less time walking compared to their healthy peers, and when they do walk, they do it at a significantly slower rate. ${ }^{30}$ In our study the average daily step count was 8059 steps/day, which is not a bad result, although still considerably less than the 10,000

Table 2 Physical Fitness and Muscle Function/Mass of the Study Population

\begin{tabular}{|l|l|}
\hline Parameter & \\
\hline Physical activity, steps/day & 8059 (4757) \\
6-minute walk distance, m & 376 (I I9) \\
4-meter gait speed, m/s & $0.89(0.22)$ \\
30-second chair stand test, number of stands & $\mathrm{I}$ I (3) \\
Timed up and go test, s & $10.3(3.3)$ \\
Handgrip strength - right hand, kg & $30.7(10.1)$ \\
Handgrip strength - left hand, kg & $29.1(9.2)$ \\
Fat-free mass index, kg/m² & $18.3(2.7)$ \\
Calf circumference, cm & $35.6(4.2)$ \\
Arm muscle area, cm ${ }^{2}$ & $48.6(12.5)$ \\
Rectus femoris cross-sectional area, $\mathrm{cm}^{2}$ & 6.0 (I.8) \\
\hline
\end{tabular}

Note: Data are presented as means (standard deviation). steps/day that is commonly recommended for health promotion. ${ }^{31}$ However, what is more interesting is that the average daily activity among the participants ranged from extremely poor (minimum 220 steps/day) to excellent (maximum 23,342 steps/day). Nonetheless, in line with previous studies, most of the PA undertaken by our patients was at a low-intensity level, that is, they spent $73 \%$ of active time walking slowly and only $4 \%$ walking quickly.

A correlation analysis of PA and different physical performance tests revealed a strong positive correlation between the daily step count and the 6MWD, and a moderate positive correlation with the 4MGS. Similarly, both tests showed a good discriminative power for the prediction of a very low level of PA, with the best

Table 3 Correlations Between the Daily Step Count and Parameters of Physical Fitness and Muscle Function/Mass

\begin{tabular}{|c|c|}
\hline & Daily Step Count \\
\hline & $\begin{array}{l}\text { Spearman Correlation } \\
\text { Coefficient rho, p-value }\end{array}$ \\
\hline 6-minute walk distance, $\mathrm{m}$ & $0.684, p<0.001$ \\
\hline 4-meter gait speed, $\mathrm{m} / \mathrm{s}$ & $0.464, p<0.001$ \\
\hline $\begin{array}{l}\text { 30-second chair stand test, } \\
\text { number of stands }\end{array}$ & $0.402, p<0.001$ \\
\hline Timed up and go test, s & $-0.463, p<0.001$ \\
\hline Handgrip strength, kg & $0.129, p=0.176$ \\
\hline Fat-free mass index, $\mathrm{kg} / \mathrm{m}^{2}$ & $0.210, p=0.027$ \\
\hline Calf circumference, $\mathrm{cm}$ & $0.167, p=0.080$ \\
\hline Arm muscle area, $\mathrm{cm}^{2}$ & $0.163, p=0.088$ \\
\hline $\begin{array}{l}\text { Rectus femoris cross-sectional } \\
\text { area, } \mathrm{cm}^{2}\end{array}$ & $0.134, p=0.161$ \\
\hline
\end{tabular}

Note: Values in bold are statistically significant $(p<0.05)$. 
A

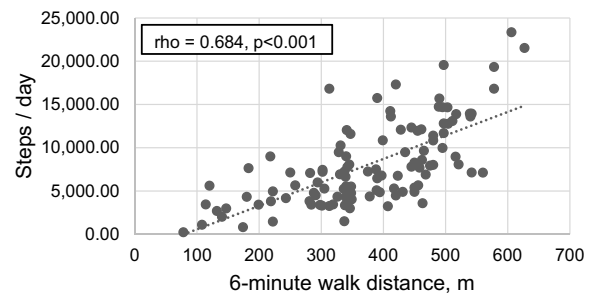

B

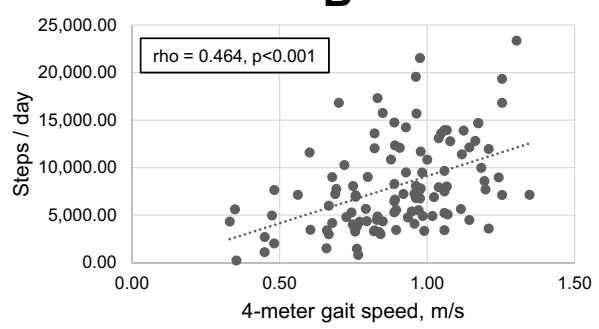

C

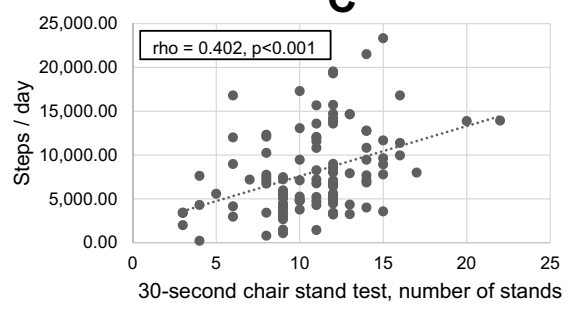

D

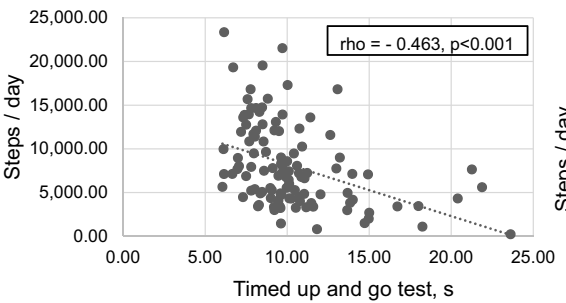

E

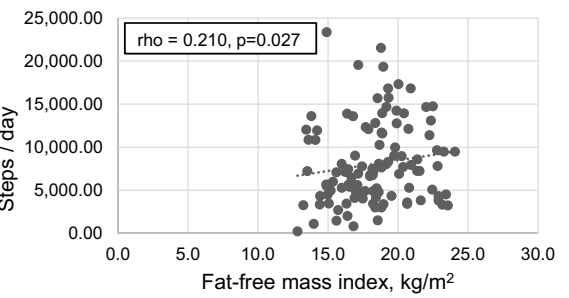

Figure 2 Significant correlations between the daily step count and parameters of physical fitness and muscle function/mass. (A) Correlation between the 6-minute walk distance and daily step count. (B) Correlation between the 4-meter gait speed and daily step count. (C) Correlation between the 30-seconds chair stand test and daily step count. (D) Correlation between the timed up and go test and daily step count. (E) Correlation between the fat-free mass index and daily step count.

threshold being $<350 \mathrm{~m}$ for the $6 \mathrm{MWD}$, and $<0.8 \mathrm{~m} / \mathrm{s}$ for the 4MGS. These results confirm the predictive value of walking tests with regard to daily activity, and they are in accordance with the findings of previous studies demonstrating, on one hand, that PA is strongly related to exercise capacity measured by the $6 \mathrm{MWD}^{30,32,33}$ and, on the other hand, has a modest association with walking speed. ${ }^{34,35}$

Table 4 Receiver Operating Characteristic (ROC) Curve Analysis of the Different Tests Used to Identify COPD Patients with a Very Low Level of Physical Activity ( $<5000$ Steps/Day)

\begin{tabular}{|c|c|c|c|c|}
\hline Test & AUC & $95 \% \mathrm{Cl}$ & $P$ value & $\begin{array}{l}\text { Best } \\
\text { Cut-Off }\end{array}$ \\
\hline $\begin{array}{l}\text { 6-minute walk } \\
\text { distance }\end{array}$ & 0.802 & $0.720-0.884$ & $<0.001$ & $350 \mathrm{~m}$ \\
\hline 4-meter gait speed & 0.698 & $0.600-0.798$ & $<0.001$ & $0.8 \mathrm{~m} / \mathrm{s}$ \\
\hline $\begin{array}{l}\text { 30-second chair } \\
\text { stand test }\end{array}$ & 0.676 & $0.576-0.776$ & 0.001 & II stands \\
\hline $\begin{array}{l}\text { Timed up and go } \\
\text { test }\end{array}$ & 0.752 & $0.658-0.846$ & $<0.001$ & $10 \mathrm{~s}$ \\
\hline Handgrip strength & 0.596 & $0.491-0.702$ & 0.082 & 30 kg \\
\hline Fat-free mass index & 0.502 & $0.440-0.752$ & 0.088 & $19 \mathrm{~kg} / \mathrm{m}^{2}$ \\
\hline Calf circumference & 0.601 & $0.496-0.707$ & 0.066 & $36 \mathrm{~cm}$ \\
\hline Arm muscle area & 0.612 & $0.506-0.718$ & 0.114 & $48 \mathrm{~cm}^{2}$ \\
\hline $\begin{array}{l}\text { Rectus femoris } \\
\text { cross-sectional area }\end{array}$ & 0.589 & $0.483-0.695$ & 0.106 & $6 \mathrm{~cm}^{2}$ \\
\hline
\end{tabular}

Abbreviations: $\mathrm{AUC}$, area under the curve; $\mathrm{Cl}$, confidence interval.
Furthermore, we found a significant correlation between daily activity and two more rapid and easy to perform tests; namely, the number of stands in the 30sCST, which showed a moderate positive correlation, and the duration of the TUGT, which had a moderate negative correlation with the daily step count. According to the ROC analysis, both tests may also be useful to detect low levels of PA, with $<11$ stands in the 30sCST and/or a duration $>10 \mathrm{~s}$ in the TUGT demonstrating good discriminative power to predict a daily step count $<5000$. The TUGT is a reliable and valid method for quantifying functional mobility and balance in frail elderly people, ${ }^{25}$ while the timed chair stand test ${ }^{36}$ was initially developed for the assessment of lower extremity muscle

Table 5 Probability of Severe Inactivity ( $<5000$ Steps/Day) Based on the Results of the Three Easy-to-Perform Tests

\begin{tabular}{|c|c|c|c|}
\hline $\begin{array}{l}\text { 4-Meter } \\
\text { Gait } \\
\text { Speed } \\
<0.8 \mathrm{~m} / \mathrm{s}\end{array}$ & $\begin{array}{l}\text { 30-Second } \\
\text { Chair Stand } \\
\text { Test < I I Stands }\end{array}$ & $\begin{array}{l}\text { Timed Up } \\
\text { and Go } \\
\text { Test }>10 \mathrm{~s}\end{array}$ & $\begin{array}{l}\text { Probability of } \\
\text { Very Low } \\
\text { Physical Activity } \\
\text { (\%) }\end{array}$ \\
\hline- & - & - & 29.4 \\
\hline+ & - & - & 42.8 \\
\hline- & + & - & 38.4 \\
\hline- & - & + & 46.9 \\
\hline+ & + & - & 52.9 \\
\hline+ & - & + & 61.4 \\
\hline- & + & + & 57.0 \\
\hline+ & + & + & 70.4 \\
\hline
\end{tabular}


strength in older people. There are several variants of this test - either to measure the time that a participant needs to stand 10 (original test), 1 or 5 times from a standard height chair with no arm support, or to measure the number of stands from a chair in 30 seconds, the $30 \mathrm{sCST}^{24}$ or in a 1-minute period. Repetitive chair-rise movements not only require lower body muscle power but also good coordination, balance, and cardiorespiratory endurance. Therefore, in recent years the repetitive chair stand test, especially the 1-min sit-to-stand test, has become a popular method for rapid measurement of functional exercise capacity in patients with different chronic diseases including COPD and has even proven to be a predictor of mortality in patients with COPD. ${ }^{37,38}$ Our findings regarding the 30sCST and the TUGT are novel, because to our knowledge no previous study has investigated the correlation between the PA of COPD patients and either of these two tests. The only comparable published data are for the 1-min sit-to-stand test, which demonstrated a moderate positive correlation with daily step count in patients with COPD in the study by van Gestel et $\mathrm{al}^{33}$ and for the five-repetition sit-to-stand test, which showed a lack of correlation with PA in a small study in 22 COPD patients published by Iwakura et al. ${ }^{39}$

Skeletal muscle mass wasting and/or dysfunction are present in about one-third of patients with COPD and have been associated with multiple negative implications, including exercise intolerance, higher health care use, reduced quality of life and increased mortality. ${ }^{40}$ Since the musculoskeletal system is crucial for any body movement, it is reasonable to assume that a reduction in FFMI, an indicator of muscle and bone mass, would lead to impaired physical performance. Measurement of FFMI requires additional equipment, such as bioelectric impedance analysis or DEXA scan, but at least some of these methods are available in most hospital settings, and they are rapid and easy to perform. The association between FFMI in COPD patients and their exercise capacity measured by the 6MWD has already been well documented in several studies, ${ }^{41,42}$ but evidence on the relation between FFMI and PA is scarce. In a previous study by our group, we showed that patients with poor PA have a lower FFMI, although neither the FFMI nor other nutritional parameters were independently associated with poor PA in the multivariate analysis. ${ }^{16}$ The only other study that has addressed this issue demonstrated a weak correlation between FFMI and the level of PA. ${ }^{35}$ Our present results contribute to the knowledge in this field and are in line with the previously mentioned study indicating that the FFMI is weakly correlated with the daily step count.
In the literature available, peripheral muscle dysfunction in the COPD population is usually demonstrated by a reduction in quadriceps and handgrip strength, or more recently by a reduction in strength of the knee flexor muscles (ischiocrural), ${ }^{43}$ and there is compelling evidence of a relation between muscle weakness and exercise limitation. ${ }^{40,44}$ However, the association between muscle strength and PA is not that straightforward; that is, some authors have demonstrated that daily activity is positively related to quadriceps and handgrip strength, ${ }^{30,35}$ while others have failed to show this relation. ${ }^{44,45}$ In the evaluation of muscle function, we measured handgrip strength, and as an alternative to measuring quadriceps strength, we used clinically more available ultrasound imaging of the quadriceps muscle with measurement of the $\mathrm{RF}_{\mathrm{CSA}}$, and neither of these two parameters were associated with the daily step count. This absence of association may be explained by the fact that apart from musculoskeletal and cardiorespiratory capabilities, PA is also influenced by psychological, sociodemographic and environmental factors which were not taken into account in the present study. ${ }^{46}$ The study also has a few other limitations that need to be addressed. We excluded patients with comorbidities that may obviously affect physical performance or nutritional status in order to minimize the influence of other factors except those which are unavoidable and the pulmonary disease itself, because otherwise the results of the study would be difficult to interpret. Therefore, the findings of this study may not be applicable to COPD patients with a highcomorbidity burden. Furthermore, PA was measured with an activity monitor and expressed as a daily step count, which limits the comparison of our results with studies that used different methodology to quantify daily activity, such as walking time, distance walked, energy expenditure, PA level, or questionnaire-derived data.

Based on the results of our study and with respect to the aforementioned limitations, we can conclude that the 6MWD, the 4MGS, the TUGT, the 30sCST, and the FFMI significantly correlate with the daily step count in the COPD population. Additionally, the 6MWD has the best predictive power to identify COPD patients who walk less than 5000 steps per day, followed by the 4MGS, the TUGT, and the 30sCST. These four tests are easy to perform and available in any clinical setting and may be used as screening tools for the identification of physically inactive COPD patients.

\section{Acknowledgments}

The purchase of four StepWatch Activity Monitors ${ }^{\circledR}$ with dedicated dock station and software was possible thanks to 
an unrestricted grant from Boehringer Ingelheim Zagreb, Croatia. The sponsor had no involvement in the study design, in the collection, analysis and interpretation of data, in the writing of the manuscript, nor in the decision to submit the article for publication.

\section{Disclosure}

Zinka Matkovic has received speaker fees from Abbot Laboratories, AstraZeneca, Berlin-Chemie Menarini and Boehringer Ingelheim, and conference grants from BerlinChemie Menarini and Pliva. Neven Tudoric has received speaker fees and conference grants from Chiesi, BerlinChemie Menarini, GlaxoSmithKline, AstraZeneca, Boehringer Ingelheim, Cipla, Sandoz, Teva and Novartis, and consulting fees from GlaxoSmithKline, AstraZeneca, Boehringer Ingelheim, TEVA, Berlin-Chemie Menarini and Novartis. Dario Rahelic has served as principal investigator or co-investigator in clinical trials of AstraZeneca, Eli Lilly, MSD, Novo Nordisk, Sanofi Aventis, Solvay and Trophos, he has received honoraria for speaking or advisory board engagements and consulting fees from Abbott, Amgen, AstraZeneca, Bayer, Boehringer Ingelheim, Eli Lilly, Lifescan - Johnson \& Johnson, Novartis, Novo Nordisk, MSD, Merck Sharp \& Dohme, Pfizer, Pliva, Roche, Salvus, Sanofi Aventis and Takeda. Marc Miravitlles has received speaker fees from AstraZeneca, Boehringer Ingelheim, Chiesi, Cipla, Menarini, Rovi, Bial, Sandoz, Zambon, CSL Behring, Grifols and Novartis, consulting fees from AstraZeneca, Boehringer Ingelheim, Chiesi, GlaxoSmithKline, Bial, Gebro Pharma, Kamada, CSL Behring, Laboratorios Esteve, Ferrer, Mereo Biopharma, Verona Pharma, TEVA, pH Pharma, Novartis, Sanofi and Grifols, and research grants from GlaxoSmithKline and Grifols. The authors report no other conflicts of interest in this work.

\section{References}

1. Bossenbroek L, de Greef MH, Wempe JB, Krijnen WP, Ten Hacken NH. Daily physical activity in patients with chronic obstructive pulmonary disease: a systematic review. COPD. 2011;8 (4):306-319. doi:10.3109/15412555.2011.578601

2. Tudor-Locke C, Washington TL, Hart TL. Expected values for steps/ day in special populations. Prev Med. 2009;49(1):3-11. doi:10.1016/j. ypmed.2009.04.012

3. Waschki B, Kirsten AM, Holz O, et al. Disease progression and changes in physical activity in patients with chronic obstructive pulmonary disease. Am J Respir Crit Care Med. 2015;192(3):295-306. doi:10.1164/rccm.201501-0081OC

4. Watz H, Pitta F, Rochester CL, et al. An official European respiratory society statement on physical activity in COPD. Eur Respir J. 2014;44 (6):1521-1537. doi:10.1183/09031936.00046814
5. Esteban C, Quintana JM, Aburto M, et al. Impact of changes in physical activity on health-related quality of life among patients with COPD. Eur Respir J. 2010;36(2):292-300. doi:10.1183/ 09031936.00021409

6. Moy ML, Teylan M, Weston NA, Gagnon DR, Garshick E. Daily step count predicts acute exacerbations in a US cohort with COPD. PLoSOne. 2013;8(4):e60400. doi:10.1371/journal.pone.0060400

7. Ramon MA, Esquinas C, Barrecheguren M, et al. Self-reported daily walking time in COPD: relationship with relevant clinical and functional characteristics. Int $J$ Chron Obstruct Pulmon Dis. 2017;12:1173-1181. doi:10.2147/COPD.S128234

8. Waschki B, Kirsten A, Holz O, et al. Physical activity is the strongest predictor of all-cause mortality in patients with COPD: a prospective cohort study. Chest. 2011;140(2):331-342. doi:10.1378/chest.10-2521

9. Chawla H, Bulathsinghala C, Tejada JP, Wakefield D, ZuWallack R. Physical activity as a predictor of thirty-day hospital readmission after a discharge for a clinical exacerbation of chronic obstructive pulmonary disease. Ann Am Thorac Soc. 2014;11(8):1203-1209. doi:10.1513/AnnalsATS.201405-1980C

10. Miravitlles M, Cantoni J, Naberan K. Factors associated with a low level of physical activity in patients with chronic obstructive pulmonary disease. Lung. 2014;192(2):259-265. doi:10.1007/s00408-0149557-x

11. Pleguezuelos E, Gimeno-Santos E, Hernández C, et al. Recommendations on non-pharmacological treatment in chronic obstructive pulmonary disease from the Spanish COPD guidelines (GesEPOC 2017). Arch Bronconeumol. 2018;54(11):568-575. doi:10.1016/j.arbres.2018.06.001

12. Pitta F, Troosters T, Probst VS, Spruit MA, Decramer M, Gosselink R. Quantifying physical activity in daily life with questionnaires and motion sensors in COPD. Eur Respir J. 2006;27 (5):1040-1055. doi:10.1183/09031936.06.00064105

13. Liao S, Benzo R, Ries AL, Soler X. Physical activity monitoring in patients with chronic obstructive pulmonary disease. J COPD F. 2014;1(2):155-165. doi:10.15326/jcopdf.1.2.2014.0131

14. Van Remoortel H, Raste Y, Louvaris Z, et al. Validity of six activity monitors in chronic obstructive pulmonary disease: a comparison with indirect calorimetry. PLoS One. 2012;7(6):e39198. doi:10.1371/journal.pone. 0039198

15. Moy ML, Danilack VA, Weston NA, Garshick E. Daily step counts in a US cohort with COPD. Respir Med. 2012;106(7):962-969. doi:10.1016/j.rmed.2012.03.016

16. Matkovic Z, Cvetko D, Rahelic D, et al. Nutritional status of patients with chronic obstructive pulmonary disease in relation to their physical performance. COPD. 2017;14(6):626-634. doi:10.1080/ 15412555.2017.1386643

17. Bestall JC, Paul EA, Garrod R, et al. Usefulness of the Medical Research Council (MRC) dyspnoea scale as a measure of disability in patients with chronic obstructive pulmonary disease. Thorax. 1999;54(7):581-586. doi:10.1136/thx.54.7.581

18. Jones PW, Harding G, Berry P, Wiklund I, Chen WH, Kline Leidy N. Development and first validation of the COPD assessment test. Eur Respir J. 2009;34(3):648-654. doi:10.1183/09031936.00102509

19. Charlson ME, Pompei P, Ales KL, MacKenzie CR. A new method of classifying prognostic comorbidity in longitudinal studies: development and validation. $J$ Chronic Dis. 1987;40(5):373-383. doi:10.1016/0021-9681(87)90171-8

20. Miller MR, Hankinson J, Brusasco V, et al. Standardisation of spirometry. Eur Respir J. 2005;26(2):319-338.doi:10.1183/ 09031936.05.00034805

21. Wanger J, Clausen JL, Coates A, et al. Standardisation of the measurement of lung volumes. Eur Respir J. 2005;26(3):511-522. doi:10.1183/09031936.05.00035005

22. Kon SS, Patel MS, Canavan JL, et al. Reliability and validity of 4-metre gait speed in COPD. Eur Respir J. 2013;42(2):333-340. doi: $10.1183 / 09031936.00162712$ 
23. ATS. Committee on proficiency standards for clinical pulmonary function laboratories. ATS statement: guidelines for the six-minute walk test. Am J Respir Crit Care Med. 2002;166(1):111-117. doi:10.1164/ajrccm.166.1.at1102

24. Jones CJ, Rikli RE, Beam WC. A 30-s chair-stand test as a measure of lower body strength in community-residing older adults. Res $Q \quad$ Exerc Sport. 1999;70(2):113-119. doi:10.1080/ 02701367.1999.10608028

25. Podsiadlo D, Richardson S. The timed "up \& go": a test of basic functional mobility for frail elderly persons. J Am Geriatr Soc. 1991;39(2):142-148. doi:10.1111/j.1532-5415.1991.tb01616.x

26. Mathiowetz V, Kashman N, Volland G, Weber K, Dowe M, Rogers S. Grip and pinch strength: normative data for adults. Arch Phys Med Rehabil. 1985;66(2):69-74.

27. WHO Expert Committee. Physical Status: The Use and Interpretation of Anthropometry: Report of a Who Expert Committee. Geneva: World Health Organization; 1995.

28. Seymour JM, Ward K, Sidhu PS, et al. Ultrasound measurement of rectus femoris cross-sectional area and the relationship with quadriceps strength in COPD. Thorax. 2009;64(5):418-423. doi:10.1136/ thx.2008.103986

29. Tudor-Locke C, Craig CL, Thyfault JP, Spence JC. A step-defined sedentary lifestyle index: $<5000$ steps/day. Appl Physiol Nutr Metab. 2013;38(2):100-114. doi:10.1139/apnm-2012-0235

30. Pitta F, Troosters T, Spruit MA, Probst VS, Decramer M, Gosselink R. Characteristics of physical activities in daily life in chronic obstructive pulmonary disease. Am J Respir Crit Care Med. 2005;171(9):972-977. doi:10.1164/rccm.200407-855OC

31. Tudor-Locke C, Craig CL, Brown WJ, et al. How many steps/day are enough? For adults. Int J Behav Nutr Phys Act. 2011;8(1):79. doi:10.1186/1479-5868-8-79

32. Watz H, Waschki B, Meyer T, Magnussen H. Physical activity in patients with COPD. Eur Respir J. 2009;33(2):262-272. doi:10.1183/ 09031936.00024608

33. Van Gestel AJR, Clarenbach CF, Stöwhas AC, et al. Predicting daily physical activity in patients with chronic obstructive pulmonary disease. PLoS One. 2012;7(11):e48081. doi:10.1371/journal. pone.0048081

34. DePew ZS, Karpman C, Novotny PJ, Benzo RP. Correlations between gait speed, 6-minute walk distance, physical activity, and self-efficacy in patients with severe chronic lung disease. Respir Care. 2013;58(12):2113-2119. doi:10.4187/respcare.02471

35. Andersson M, Slinde F, Grönberg AM, Svantesson U, Janson C, Emtner M. Physical activity level and its clinical correlates in chronic obstructive pulmonary disease: a cross-sectional study. Respir Res. 2013;14(1):128. doi:10.1186/1465-9921-14-128
36. Csuka M, McCarty DJ. Simple method for measurement of lower extremity muscle strength. Am J Med. 1985;78(1):77-81. doi:10.1016/0002-9343(85)90465-6

37. Crook S, Büsching G, Schultz K, et al. A multicentre validation of the 1-min sit-to-stand test in patients with COPD. Eur Respir J. 2017;49(3):1601871. doi:10.1183/13993003.01871-2016

38. Puhan MA, Siebeling L, Zoller M, Muggensturm P, Ter Riet G. Simple functional performance tests and mortality in COPD. Eur Respir J. 2013;42(4):956-963. doi:10.1183/09031936.00131612

39. Iwakura M, Okura K, Shibata K, et al. Relationship between balance and physical activity measured by an activity monitor in elderly COPD patients. Int $J$ Chron Obstruct Pulmon Dis. 2016;11:1505-1514. doi:10.2147/COPD.S107936

40. Maltais F, Decramer M, Casaburi R, et al. An official American Thoracic Society/European Respiratory Society statement: update on limb muscle dysfunction in chronic obstructive pulmonary disease. Am J Respir Crit Care Med. 2014;189(9):e15-62. doi:10.1164/rccm.201402-0373ST

41. Luo Y, Zhou L, Li Y, et al. Fat-free mass index for evaluating the nutritional status and disease severity in COPD. Respir Care. 2016;61 (5):680-688. doi:10.4187/respcare.04358

42. Ischaki E, Papatheodorou G, Gaki E, Papa I, Koulouris N, Loukides S. Body mass and fat-free mass indices in COPD: relation with variables expressing disease severity. Chest. 2007;132 (1):164-169. doi:10.1378/chest.06-2789

43. Pleguezuelos E, Guirao L, Moreno E, et al. Ischiocrural strength may be a better prognostic marker than quadriceps strength in COPD. Lung. 2018;196(6):665-668. doi:10.1007/s00408-018-0164-0

44. Rausch-Osthoff AK, Kohler M, Sievi NA, Clarenbach CF, van Gestel AJ. Association between peripheral muscle strength, exercise performance, and physical activity in daily life in patients with chronic obstructive pulmonary disease. Multidiscip Respir Med. 2014;9(1):37. doi:10.1186/2049-6958-9-37

45. Watz H, Waschki B, Boehme C, Claussen M, Meyer T, Magnussen H. Extrapulmonary effects of chronic obstructive pulmonary disease on physical activity: a cross-sectional study. Am $J$ Respir Crit Care Med. 2008;177(7):743-751. doi:10.1164/ rccm.200707-10110C

46. Miravitlles M, Troosters T, Janssens W, Ancochea J. Multidisciplinary perspectives on the importance of physical activity in COPD. Arch Bronconeumol. 2019;55(11):551-552. doi:10.1016/j. arbres.2019.03.010

\section{Publish your work in this journal}

The International Journal of COPD is an international, peer-reviewed journal of therapeutics and pharmacology focusing on concise rapid reporting of clinical studies and reviews in COPD. Special focus is given to the pathophysiological processes underlying the disease, intervention programs, patient focused education, and self management protocols. This journal is indexed on PubMed Central, MedLine and CAS. The manuscript management system is completely online and includes a very quick and fair peer-review system, which is all easy to use. Visit http://www.dovepress.com/testimonials.php to read real quotes from published authors. 